\title{
Direct Power Control Strategy of PWM Rectifier Based on Improved Virtual Flux-Linkage Observer
}

\author{
Wenshao BU and Leilei Xu \\ Electrical Engineering College, Henan University of Science and Technology, Luoyang 471023, China \\ Correspondence should be addressed to Wenshao BU; wsbu@163.com
}

Received 16 May 2017; Revised 13 August 2017; Accepted 27 August 2017; Published 2 October 2017

Academic Editor: Fabio Mottola

Copyright (C) 2017 Wenshao BU and Leilei Xu. This is an open access article distributed under the Creative Commons Attribution License, which permits unrestricted use, distribution, and reproduction in any medium, provided the original work is properly cited.

\begin{abstract}
In order to achieve the low cost and high performance control of three-phase PWM rectifier, a direct power control (DPC) strategy based on a new-style virtual flux-linkage observer is proposed. The model of three-phase PWM rectifier and the principle of virtual flux-linkage vector control are introduced firstly. Then, in order to avoid the effect of integral initial value and cumulative deviation, three first-order low-pass filters are cascaded to replace the pure integral link; an improved virtual flux-linkage observer of threephase power grid is presented. From the observed virtual flux-linkage, the voltage and instantaneous power of three-phase power grid are online estimated. On this basis, the power grid voltage sensorless direct power control system of three-phase PWM rectifier is designed. Simulation results have shown that, both in the rectifying state and in the inverting state, the power grid side current and the DC side voltage of three-phase PWM rectifier all can be effectively controlled; the high power factor operation of three-phase PWM rectifier is realized.
\end{abstract}

\section{Introduction}

Compared with the conventional uncontrolled rectifier using diodes, adopting three-phase PWM rectifier, the energy can be controlled to freely flow along positive and negative directions $[1,2]$. When the PWM rectifier technology is applied to back to back converter, photovoltaic grid connected inverter, power active filter, and so on, the power factor of system can be improved greatly, and the harmonic and reactive pollution to the grid can be effectively reduced $[1,3,4]$. And then, it has a broad application prospects in modern power system and equipment [5-8].

With the development of power electronics and control theory, in order to improve the control performance and reduce system cost and harmonics, numerous modern control strategies have been studied and applied in an attempt to the control system of three-phase PWM rectifier [9-15]. Hereinto, direct power control (DPC) strategy has become one of the hot research topics in recent years, because of its fast dynamic response, simple structure, and high power factor, and so on $[8,11,12,14,16-18]$. In general station, the control system of PWM rectifier contains more sensors and complex detection device, which not only increases the volume of the system device and improves the system cost, but also reduces the system reliability of three-phase PWM rectifier. The common used sensors in the control system of three-phase PWM rectifier include DC voltage sensor, power grid voltage sensors, and $\mathrm{AC}$ current sensors on power grid side. The AC current sensor is used to detect the AC current on power grid side of PWM rectifier and used for the closedloop control of incoming line current; it plays an important role in the over-current protection of PWM rectifier system. The DC voltage sensor is used to detect the level and stability of DC bus voltage and used for the closed-loop control of DC side voltage. The AC current and DC voltage sensors play a crucial role in ensuring the control performance of three-phase PWM rectifier system. Even in the DPC control system of three-phase PWM rectifier, the incoming line AC current and the DC side voltage are also necessary to calculate instantaneous power variables $[2,8,11,12,14,19]$. And then, the two sensors are generally not to be omitted in actual application.

As for the power grid voltage, it can be obtained from online identification $[2,10,13,15]$. If the power grid voltage 
sensor can be saved, the system performance would not be affected by too much; meanwhile the system structure can be more conducive to simplifying, the system costs can be reduced also. The power grid side of three-phase PWM rectifier is similar to the stator structure of common threephase AC motor driven by a three-phase inverter; the power grid can be seen as a virtual AC motor; its virtual fluxlinkage can be used to estimate the power grid voltage of three-phase PWM rectifier. And then, the vector control method based on virtual flux oriented is widely used to the power grid voltage sensorless control scheme of threephase PWM rectifier. But, in the conventional virtual fluxlinkage observer, there exists a pure integral link, and then the estimation process of virtual power grid flux-linkage is inevitably affected by the initial value and the cumulative deviation of the integrator $[2,20-23]$. In order to overcome the deficiencies of pure integrator, a first-order low-pass filter is adopted to replace the pure integrator; the initial value problem of pure integrator can be successfully solved [13]; however, the problem of amplitude and phase deviation is caused. About the direct power control (DPC) of three-phase PWM rectifier without power grid voltage sensor, preliminary research progress has been made [24, 25]; however, the integral initial value and cumulative deviation of pure integrator remain to be solved. In order to overcome the influence of integral initial value and cumulative deviation of pure integrator and avoid the amplitude and phase deviation caused by first-order low-pass filter, three first-order lowpass filters are cascaded to replace the pure integrator; an improved virtual flux-linkage observer is proposed in [2]; but the working principle of virtual flux oriented vector control system is not introduced in detail; moreover, the improved virtual flux-linkage observation method is not combined with the DPC system of three-phase PWM rectifier.

In this paper, based on the existing technology, the characteristic of virtual flux-linkage is further analyzed, and an improved virtual flux-linkage observation scheme is adopted; the observation scheme can effectively avoid the influence of integral initial value and cumulative deviation of pure integrator. Based on the improved virtual flux-linkage observer, the power grid voltage sensorless DPC strategy of a three-phase PWM rectifier is proposed. Simulation results have verified the validity and feasibility of the proposed control strategy.

\section{Power Grid Voltage Sensorless Control Principle}

Figure 1 shows the circuit topology of three-phase PWM rectifier. In Figure 1: $u_{a}, u_{b}$, and $u_{c}$ are the AC side voltages; $e_{a}, e_{b}$, and $e_{c}$ are the three-phase power grid voltage, that is, the three-phase EMF of power grid; $i_{a}, i_{b}$, and $i_{c}$ are the AC side current of three-phase PWM rectifier; $u_{\mathrm{dc}}$ is the DC side voltage of three-phase PWM rectifier; $R$ is the resistance of line reactor; $L$ is the inductance of line reactor; $C$ is the capacitor on DC side; $i_{L}$ is the load current.

For the convenience of analysis, assume that the threephase power grid voltage is symmetrical, neglecting the switch delay.

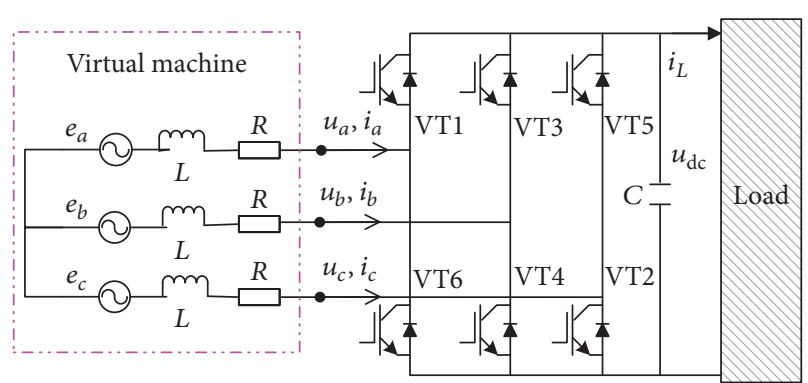

FIGURE 1: Topology of three-phase PWM rectifier.

Defining $s_{k}$ as the switching function of three-phase PWM rectifier, if the upper bridge arm is "ON," $s_{k}=1$; if the lower bridge arm is "ON," $s_{k}=0$, where $k=a, b, c$. Then, in three-phase stationary coordinate system, the basic model of three-phase PWM rectifier can be expressed as follows:

$$
\begin{aligned}
e_{k} & =L \frac{d i_{k}}{d t}+R i_{k}+u_{k} \\
C \frac{d u_{\mathrm{dc}}}{d t} & =\sum i_{k} s_{k}-i_{L} .
\end{aligned}
$$

In (1) $e_{k}$ represents the power grid phase voltage; $i_{k}$ represents the AC side current; $u_{k}$ represents the AC side voltage of PWM rectifier, where $k=a, b, c$, and the following is the same as this.

According to the topology construct of three-phase PWM rectifier, the AC side voltage $u_{k}$ can be expressed by the DC side voltage and switching functions. The expression of $u_{k}$ can be derived as follows:

$$
u_{k}=u_{\mathrm{dc}}\left[s_{k}-\frac{1}{3}\left(\sum s_{k}\right)\right] .
$$

Substituting (2) into (1), the expression of power grid voltage can be derived as follows:

$$
e_{k}=L \frac{d i_{k}}{d t}+R i_{k}+u_{\mathrm{dc}}\left[s_{k}-\frac{1}{3}\left(\sum s_{k}\right)\right] .
$$

From (3), it can be known that, based on the DC side voltage, AC side current, and the switching status of power electronic device, the power grid voltages $e_{a}, e_{b}$, and $e_{c}$ can be reconstructed; that is, the power grid voltage can be online observed. This is the theoretical basis of the power grid voltage observation.

\section{Improved Virtual Flux-Linkage Observer}

From Figure 1, it can be seen that the circuit topology of a three-phase PWM rectifier is similar to that of a three-phase AC electric machinery supplied by a three-phase inverter. So the part within the dashed box can be seen as a virtual synchronous AC motor $[2,10]$. And then, the power grid voltage can be regarded as the differential quantity of the virtual flux-linkage of virtual AC electric machinery; the phase information of power grid can be obtained from the 
virtual flux orientation, so that the power grid voltage sensor can be omitted.

In stationary $\alpha \beta$ coordinate system, if the resistance $R$ of reactor can be omitted, the voltage equation of three-phase PWM rectifier can be expressed as follows:

$$
\begin{aligned}
& e_{\alpha}=L \frac{d i_{\alpha}}{d t}+u_{\alpha} \\
& e_{\beta}=L \frac{d i_{\beta}}{d t}+u_{\beta},
\end{aligned}
$$

where $e_{\alpha}, e_{\beta}$ and $i_{\alpha}, i_{\beta}$, respectively, represent the power grid voltage components and power grid currents components in $\alpha \beta$ coordinate system; $u_{\alpha}$ and $u_{\beta}$ are the AC side voltage components of three-phase PWM rectifier in $\alpha \beta$ coordinate system.

In $\alpha \beta$ coordinate system, according to the DC side voltage and the switching status of three-phase PWM rectifier $S_{k}(k=$ $a, b, c)$, the AC side voltage components of three-phase PWM rectifier can be estimated as follows:

$$
\begin{aligned}
& u_{\alpha}=\frac{2}{3} u_{\mathrm{dc}}\left(s_{a}-\frac{s_{b}+s_{c}}{2}\right) \\
& u_{\beta}=\frac{\sqrt{3}}{3} u_{\mathrm{dc}}\left(s_{b}-s_{c}\right) .
\end{aligned}
$$

Substituting (5) into (4), the estimation expressions of power grid voltage components $e_{\alpha}$ and $e_{\beta}$ can be obtained. But in (4), there exists a differential calculation link of current variable, and it is easy to introduce interference in actual application $[9,15,16,19,23]$. Then, Taking integral operation for the both sides of (4), and combining the relationship between flux-linkage and electromotive force, the following equations can be derived:

$$
\begin{aligned}
& \psi_{\alpha}=\int e_{\alpha} d t=\int u_{\alpha} d t+L i_{\alpha} \\
& \psi_{\beta}=\int e_{\beta} d t=\int u_{\beta} d t+L i_{\beta},
\end{aligned}
$$

where $\psi_{\alpha}$ and $\psi_{\beta}$ are the virtual flux-linkage components along $\alpha$ and $\beta$ coordinate axes.

From the upper model analysis of three-phase PWM rectifier, it can be known that the virtual flux-linkage components $\psi_{\alpha}$ and $\psi_{\beta}$ can be obtained according to the AC side voltage and current components; and the required $\mathrm{AC}$ side voltage can be calculated online according to the DC side voltage and the switching signals $S_{k}(k=a, b, c)$.

Figure 2 shows the stable vector diagram of a three-phase PWM rectifier based on virtual flux-linkage orientation. In Figure 2, the power grid voltage vector is ahead of the virtual flux-linkage $\pi / 2$ radius; $\theta$ is the space position electric angle of virtual flux-linkage. The accurate observation of $\theta$ angle is the core task of virtual flux-linkage observer.

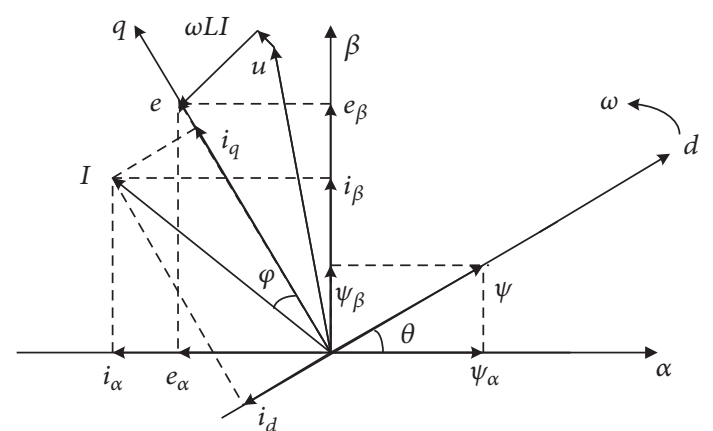

FIGURE 2: Stable vector diagram of WM rectifier based on virtual flux orientation.

From Figure 2, there are the following equations:

$$
\begin{aligned}
& \sin \theta=\frac{\psi_{\beta}}{\sqrt{\psi_{\alpha}^{2}+\psi_{\beta}^{2}}} \\
& \cos \theta=\frac{\psi_{\alpha}}{\sqrt{\psi_{\alpha}^{2}+\psi_{\beta}^{2}}} .
\end{aligned}
$$

The observation of $\theta$ angle is in fact that of the virtual fluxlinkage components along $\alpha$ and $\beta$ coordinate axes. From (6), the power grid virtual flux-linkage components along $\alpha$ and $\beta$ coordinate axes can be obtained. But there exists pure integral link in (6). If the pure integrator is adopted in the observer of power grid virtual flux, its integral initial value and cumulative deviation should be properly considered. In this paper, three first-order inertial link or first-order low-pass filters are cascaded to realize the function of pure integrator [2]. Figure 3 is the principle diagram of the adopted power grid virtual flux-linkage observer.

From the frequency domain characteristics analysis of pure integrator, it is known that, after integration, the amplitude is reduced to the original $1 / \omega$, and the phase is lagged $\pi / 2$ radian. To displace the pure integrator, the amplitude and phase characteristics of the adopted cascaded three first-order inertial links should be coincident with the pure integrator. The transfer function of the cascaded three first-order inertial links can be expressed as follows:

$$
W_{s}=\left(\frac{N}{S+\omega_{c}}\right)^{3}
$$

To satisfy the amplitude and phase relationship of pure integrator, the following relationship is necessary:

$$
\begin{gathered}
\frac{N^{3}}{\left(\omega^{2}+\omega_{c}^{2}\right)^{3 / 2}}=\frac{1}{\omega} \\
3 \arctan \left(\frac{\omega}{\omega_{c}}\right)=90^{\circ} .
\end{gathered}
$$




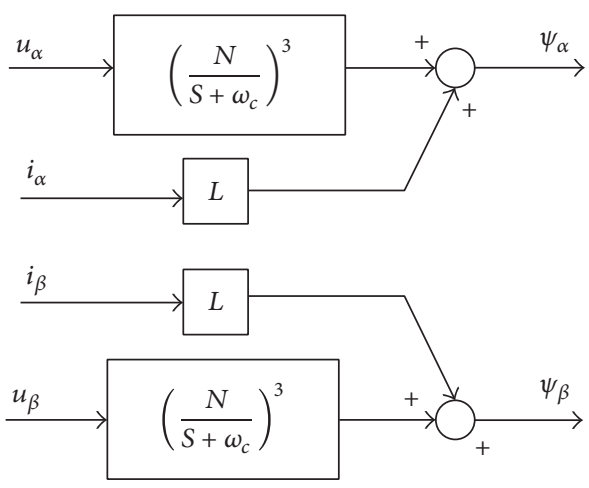

Figure 3: New virtual flux-linkage observer.

From (9), the parameter of cascaded first-order inertial links can be derived as follows:

$$
\begin{aligned}
& N=2 \sqrt[3]{\omega^{2}} \\
& \omega_{c}=\sqrt{3} \omega,
\end{aligned}
$$

where $\omega_{c}$ is the cutoff frequency of first-order inertial link; $\omega$ is the angular frequency of power grid voltage; its value is $314 \mathrm{rad} / \mathrm{s}$.

When the parameters of the required first-order inertial link are calculated according to (10), the pure integrator in (6) can be displaced by cascaded three first-order inertial links, and the power grid voltage sensorless control of threephase PWM rectifier can be achieved. Thus, not only the influence of integral initial value and cumulative deviation on the output signal can be overcome, but also the amplitude and phase of output signals have no errors again; the phase difference between the output signal and the input signal always keeps $\pi / 2$ radian.

\section{DPC System Based on Improved Virtual Flux Observer}

4.1. Power Grid Voltage Estimation Based on Virtual FluxLinkage. When the DPC strategy of three-phase PWM rectifier is adopted, the instantaneous power estimation should be made $[14,17-19,25]$. To simplify the complex coordinate transformation, the instantaneous power of DPC system should always be estimated in stationary $\alpha \beta$ coordinate system. According to (6), the virtual flux-linkage is observed, and then, combining the relationship $e=d \psi / d t$, the estimation of power grid voltage vector can be expressed as follows:

$$
e=\frac{d \psi}{d t}=\frac{d\left(\psi_{m} e^{j \omega t}\right)}{d t}=\frac{d \psi_{m}}{d t} e^{j \omega t}+\omega \psi_{m} e^{j(\omega t+\pi / 2)},
$$

where $\psi$ is virtual power grid flux-linkage vector; $\psi_{m}$ is amplitude of $\psi$.

If the virtual power grid flux-linkage vector $\psi$ is expressed as " $\psi=\psi_{\alpha}+j \psi_{\beta}$," then along $\alpha \beta$ coordinate system, the components of power grid voltage vector $e$ can be expressed as follows:

$$
\begin{aligned}
& e_{\alpha}=\frac{d \psi_{m}}{d t} \cos (\omega t)-\omega \psi_{\beta} \\
& e_{\beta}=\frac{d \psi_{m}}{d t} \sin (\omega t)+\omega \psi_{\alpha} .
\end{aligned}
$$

4.2. Instantaneous Power Estimation Based on Virtual FluxLinkage. According to the three-phase instantaneous power theory, there is the following equation:

$$
\begin{gathered}
e \cdot i^{*}=\left\{i_{\alpha}\left[\frac{d \psi_{m}}{d t} \cos (\omega t)-\omega \psi_{\beta}\right]\right. \\
\left.+i_{\beta}\left[\frac{d \psi_{m}}{d t} \sin (\omega t)+\omega \psi_{\alpha}\right]\right\} \\
+j\left\{i_{\alpha}\left[\frac{d \psi_{m}}{d t} \sin (\omega t)+\omega \psi_{\alpha}\right]\right. \\
\left.-i_{\beta}\left[\frac{d \psi_{m}}{d t} \cos (\omega t)-\omega \psi_{\beta}\right]\right\} .
\end{gathered}
$$

In (13), $i^{*}=i_{\alpha}-j i_{\beta}$, is conjugate vector of the AC side current vector of three-phase PWM rectifier.

According to following definitions of active and reactive powers:

$$
\begin{aligned}
& p=R_{e}\left(e \cdot i^{*}\right) \\
& Q=I_{m}\left(e \cdot i^{*}\right) .
\end{aligned}
$$

The computational expressions of active and reactive powers can be derived as follows:

$$
\begin{aligned}
P=i_{\alpha} & {\left[\frac{d \psi_{m}}{d t} \cos (\omega t)-\omega \psi_{\beta}\right] } \\
& +i_{\beta}\left[\frac{d \psi_{m}}{d t} \sin (\omega t)+\omega \psi_{\alpha}\right] \\
Q=i_{\alpha} & {\left[\frac{d \psi_{m}}{d t} \sin (\omega t)+\omega \psi_{\alpha}\right] } \\
& -i_{\beta}\left[\frac{d \psi_{m}}{d t} \cos (\omega t)-\omega \psi_{\beta}\right] .
\end{aligned}
$$

For the three-phase power grid voltage is balanced, the variation rate of the flux-linkage amplitude is zero. Then, the calculation expressions of instantaneous active and reactive powers can be simplified as follows:

$$
\begin{aligned}
& P=\omega\left(\psi_{\alpha} i_{\beta}-\psi_{\beta} i_{\alpha}\right) \\
& Q=\omega\left(\psi_{\alpha} i_{\alpha}+\psi_{\beta} i_{\beta}\right) .
\end{aligned}
$$

From (16), it can be seen that, under the conditions of symmetrical power grid and non-power grid voltage sensor, the real time estimation of active power and reactive power can be achieved. 


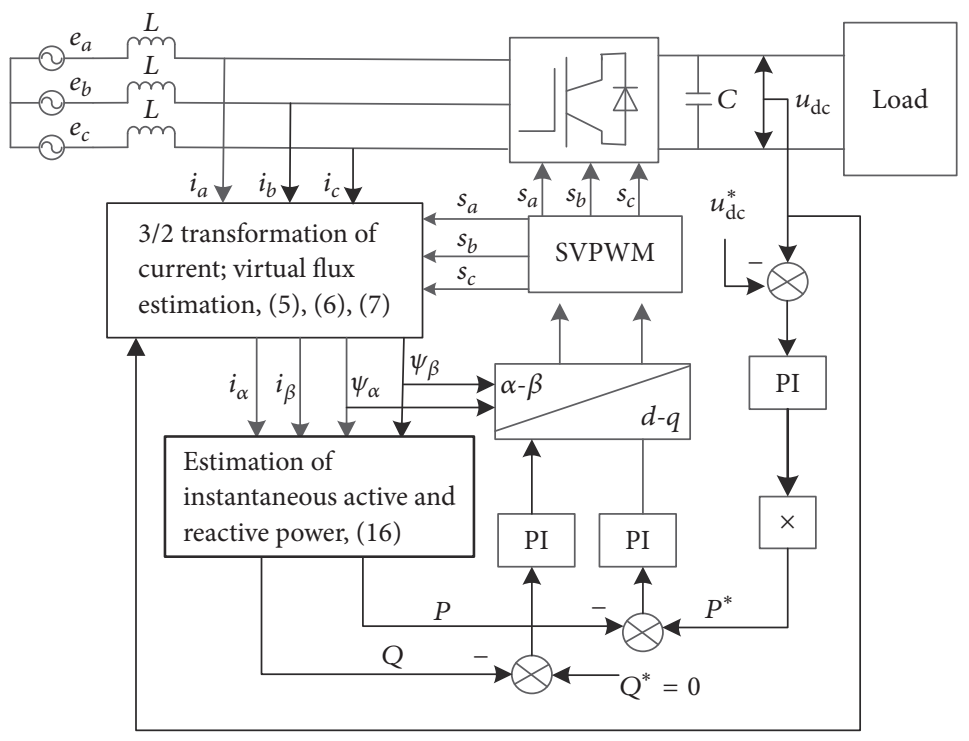

FIGURE 4: DPC system based on new virtual flux-linkage observer.

4.3. Direct Power Control System Based on Virtual FluxLinkage. Based on improved virtual flux-linkage observer, Figure 4 presents the structure diagram of power grid voltage sensorless DPC system. In Figure 4

(1) according to (5) and (6), the virtual flux-linage components $\psi_{\alpha}$ and $\psi_{\beta}$ are online calculated; then, according to (7), the phase angle $\theta$ of virtual fluxlinage is derived, which is used for the coordinate transformation of vector control system, so as to ensure that the power grid side current is sinusoidal and ensure the control system of three-phase PWM rectifier has a good dynamic response capability;

(2) in the control system of three-phase PWM rectifier, two inner loops of instantaneous active and reactive powers and an outer loop of DC voltage are adopted; the given signal of active power comes from the output of DC voltage regulator; to achieve the unit power factor control of three-phase PWM rectifier, the given signal of reactive power is set to zero; the outputs of power regulators are used as the given signal of AC side voltage of three-phase PWM rectifier; then by voltage space vector pulse-widthmodulation (SVPWM), the AC side currents of threephase PWM rectifier, that is, the output currents of three-phase power grid, are controlled;

(3) for the power grid voltage signal can be indirectly calculated from the virtual power grid flux-linkage, then the power grid voltage sensor can be saved, and the control system cost can be effectively improved.

4.4. Simulation Verification and Analysis. According to the control system structure in Figure 4, the simulation model of DPC system without power grid voltage sensor is established by MATLAB/Simulink. Table 1 gives the main simulation parameters and data.
TABLE 1: Simulation parameters and data.

\begin{tabular}{lcc}
\hline Parameter & Value & Unit \\
\hline Power grid voltage amplitude & $110 \sqrt{2}$ & $\mathrm{~V}$ \\
Given voltage on DC side & 400 & $\mathrm{~V}$ \\
Capacitor on DC bus & 5500 & $\mu \mathrm{F}$ \\
Inductance of line reactor & 1.0 & $\mathrm{mH}$ \\
\hline
\end{tabular}

Figures 5, 6, and 7 present the waveforms of a threephase PWM rectifier working in rectifying state. From the simulation results in Figures 5 and 6, it can be seen that during the system starting stage, the DC side voltage of three-phase PWM rectifier increases at a constant and rapid speed, and, at $0.03 \mathrm{~s}$, the control system reaches its steady status. The overshoot of DC side voltage is about $23 \mathrm{~V}$; after about $0.03 \mathrm{~s}$, the Phase of phase current on AC side is accordant with that of power grid phase voltage; the DC side voltage keeps at its given value at higher precision.

Figure 7 shows the instantaneous active and reactive powers waveforms during the system starting stage. At the start of the system, for the DC voltage has not been established, the reactive power is required to charge the capacitor; after the DC voltage is established, the reactive power is restored to zero. As for the active power, on the start moment, it has an overshoot; when system reaches its steady-state, it stabilizes at a steady value that matches the load.

Figure 8 presents the waveform when the PWM rectifier is working in inversing state. Apart from the transient starting stage of control system, the phase of phase current on AC side is always opposite to that of power grid phase voltage.

From the waveforms presented in Figures 6 and 8, it can be seen that whether in rectifying state or in inversing state, the three-phase PWM rectifier system all can work with a higher power factor. 


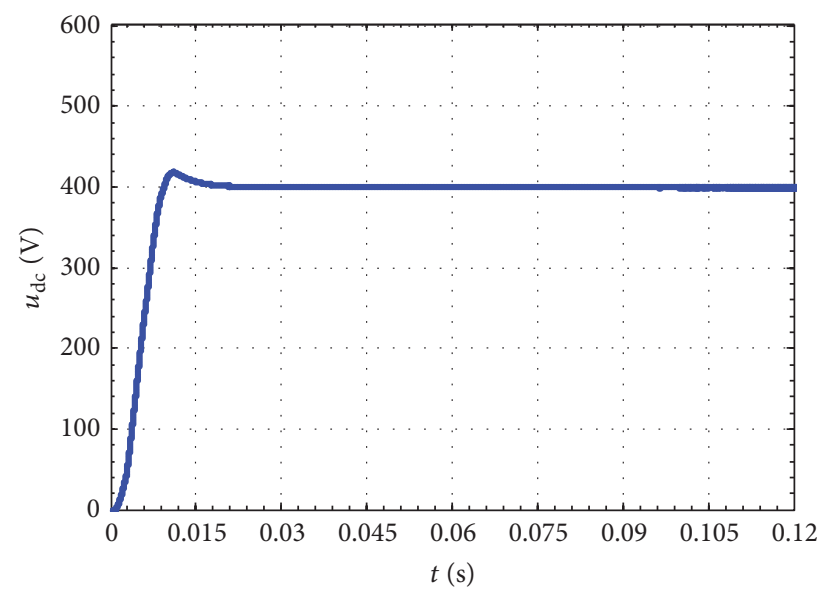

FIGURE 5: Waveform of DC bus voltage.

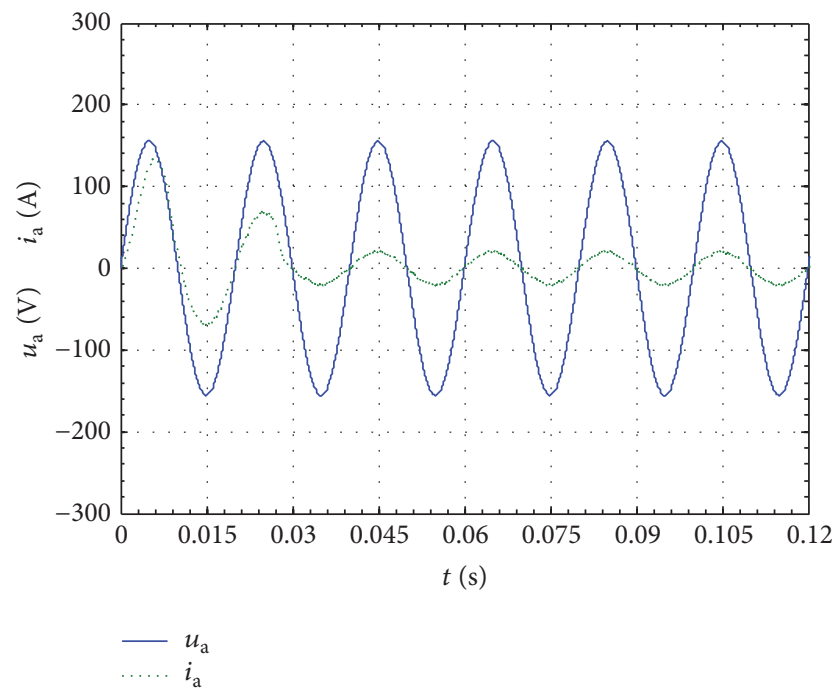

FIgURE 6: $A$-phase voltage and current waveforms in rectifier state.

When the given DC voltage signal increases from $400 \mathrm{~V}$ to $500 \mathrm{~V}$ at a certain speed, Figure 9 presents the response waveforms of three-phase PWM rectifier, including waveform of DC side voltage, waveforms of phase voltage, phase current, and the instantaneous power response curves. From Figures 9(a) and 9(b), it can be seen that, along with the DC voltage rising, under the action of the DPC control system, after a short adjustment process, the DC voltage quickly reaches a new steady-state value; whether in steady or dynamic processes, the $A$-phase AC current is always in the same phase with the $A$-phase AC voltage. That is, the threephase PWM rectifier system always runs on unit power factor status. Figure 9(c) presents the response waveforms of active power $P$ and reactive power $Q$. From Figure 9(c), it can be seen that either in steady status or in the changing process of DC voltage, the reactive power can be well controlled in zero. During the rising process of DC voltage, the active power holds a stable higher value to make sure that the DC side

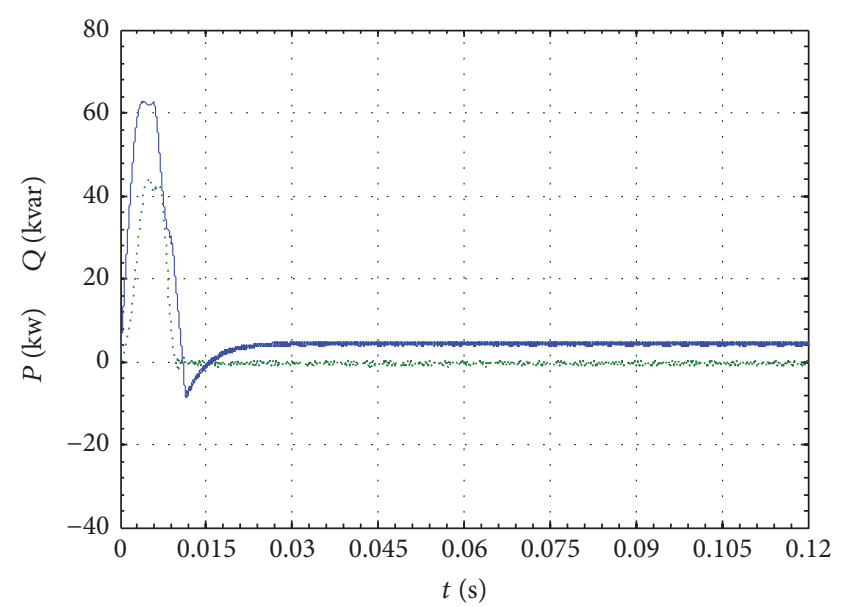

Q

$-P$

Figure 7: Waveforms of active power $P$ and reactive power $Q$.

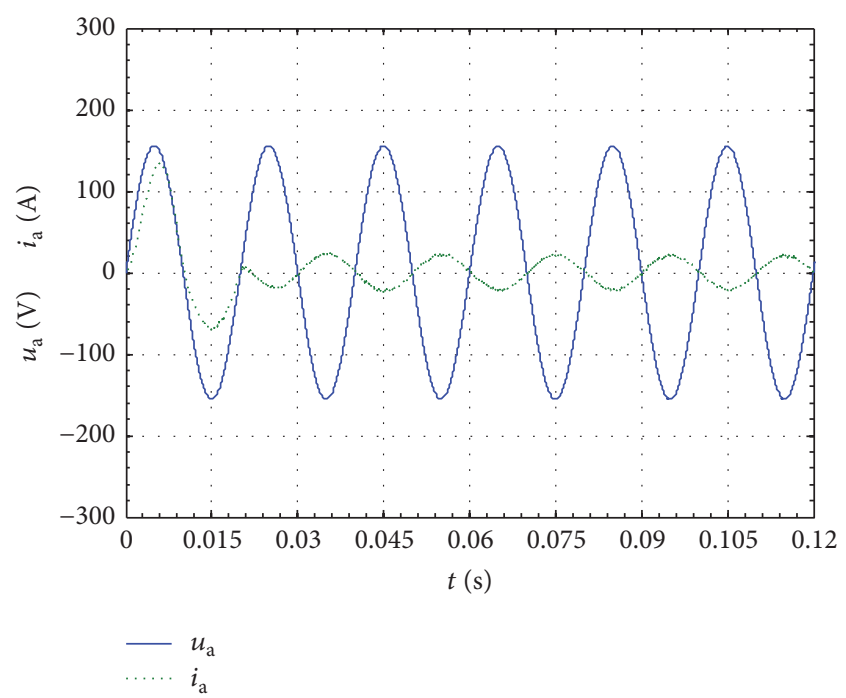

Figure 8: $A$-phase voltage and current waveforms in inverter state.

voltage rises at a certain speed. After reaching a new steadystate, the active power is maintained in a new steady value that matches the load.

Figure 10 gives the polar coordinates of power grid virtual flux-linkage observation waveform when the effective value of power grid phase voltage is set to $110 \sqrt{2}(\mathrm{~V})$.

The simulation results have shown that the DPC system based on new virtual flux-linkage observer can achieve the quasi time optimal control of three-phase PWM rectifier.

\section{Conclusion and Discussions}

In order to realize the high performance and low cost control of a three-phase PWM rectifier, based on the improved virtual flux-linkage observer, a power grid voltage sensorless direct power control (DPC) strategy is proposed. In this paper, the topology structure of three-phase PWM rectifier, 


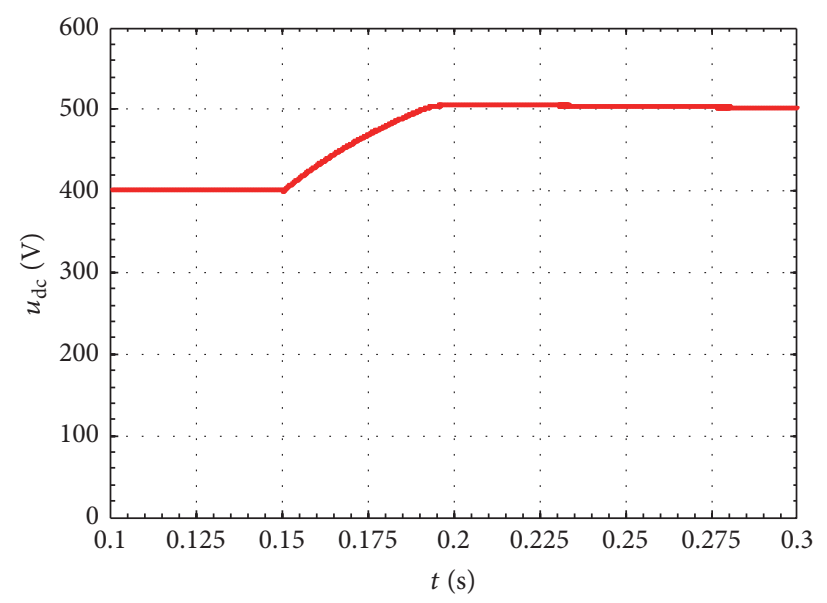

(a) DC side voltage

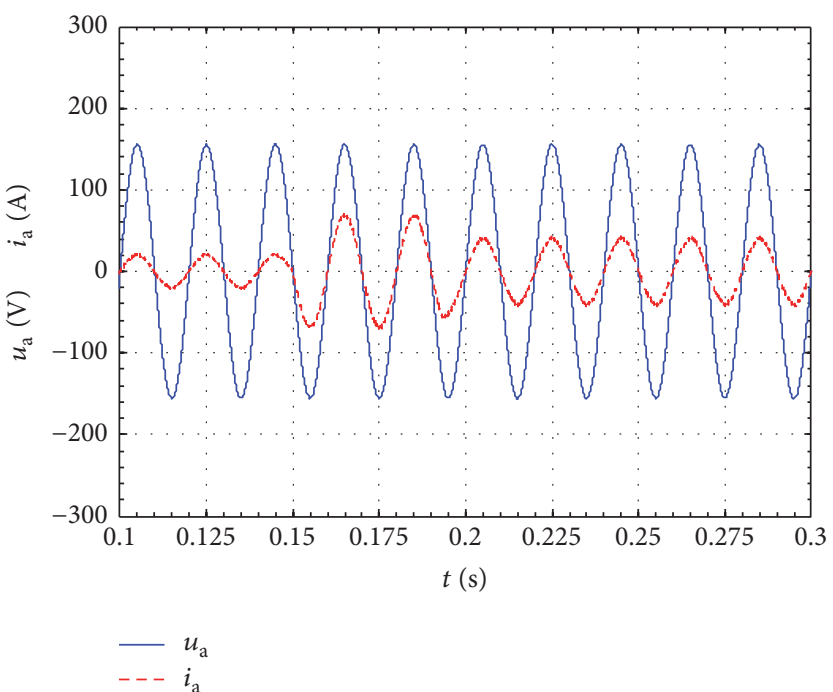

(b) Voltage and current waveform of $A$-phase

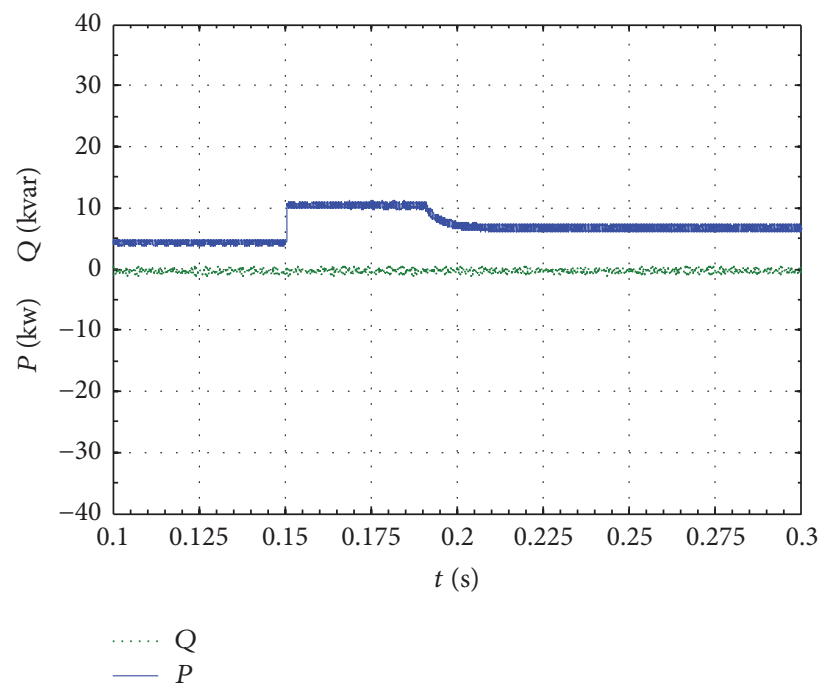

(c) Waveforms of active power $P$ and reactive power $Q$

FIGURE 9: Waveforms when increasing DC voltage.

and the observation principle of power grid voltage based on virtual flux-linkage, are introduced firstly. Aiming at the initial value and the cumulative deviation problems of pure integrator, three first-order low-pass filters in series are adopted to displace the pure integrator in the virtual fluxlinkage observer; an improved virtual flux-linkage observer is constructed. On this basis, the improved power grid voltage estimation method and the DPC algorithm are proposed; the DPC system of three-phase PWM rectifier without power grid voltage sensor is designed. Simulation verification and analyses have been made. The research conclusions can be summarized as follows:

(1) Adopting the proposed DPC strategy based on improved virtual flux-linkage observer, the initial value and the cumulative deviation problems of pure integrator can be avoided. Whether in rectifying state or in inversing state, the three-phase PWM rectifier all can work with a higher power factor. That is, when working in rectifying state, the phase of AC side current is accordant with that of power grid voltage; when working in inversing state, the phase of AC side current is always opposite to that of power grid voltage.

(2) Apart from the transient starting stage, the DC side voltage always maintains and stabilizes at its given value, whether in steady or dynamic processes. And then the DC side voltage has a higher DC voltage stability.

(3) During changing process of DC side voltage, under the action of the proposed power grid voltage sensorless DPC system, after a short adjustment process, the DC side voltage can quickly reach its steady-state value; whether in steady or dynamic processes, the 


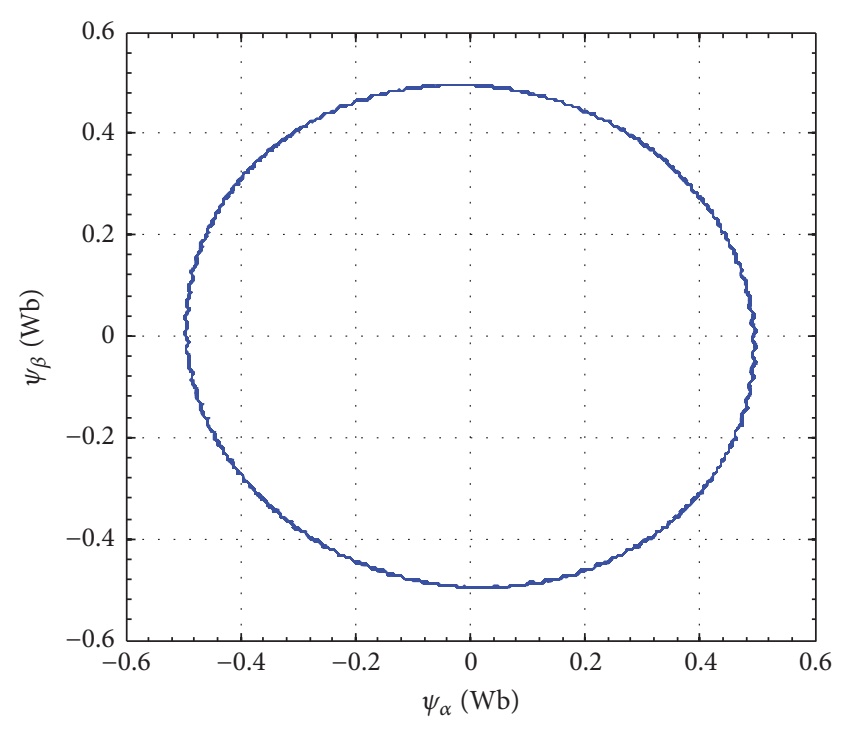

FIgURE 10: Trajectory of virtual flux-linkage.

three-phase PWM rectifier system always runs on unit power factor status.

(4) Under the action of the proposed power grid voltage sensorless DPC system, apart from the transient dynamic adjustment process, the reactive power always keeps at zero; and the active power always stabilizes at a steady value that matches the load.

(5) Based on the proposed control strategy, the power grid voltage sensorless DPC system can obtain an excellent dynamic and static control performance. Then the proposed power grid voltage sensorless DPC strategy based on improved virtual flux-linkage is effective and feasible.

Although a higher dynamic and static control performance of a three-phase PWM rectifier system is achieved, the starting time is still up to 0.03 seconds, and the overshoot of $\mathrm{DC}$ side voltage is still up to about $23 \mathrm{~V}$. And then, in order to shorten the adjustment time and DC side voltage overshoot during starting stage, how to optimize the algorithms of DC side voltage regulator and instantaneous power regulator is the next important issue to be studied.

\section{Conflicts of Interest}

All authors declare they have no conflicts of interest.

\section{Acknowledgments}

The supports of Natural Science Foundation of China (51277053), International Cooperation Project on Sci. and Tech. of Henan Province (114300510029), and Nature Science Fund of Henan Province Education Bureau (2010B510011) are acknowledged.

\section{References}

[1] M. Alam, W. Eberle, D. S. Gautam, C. Botting, N. Dohmeier, and F. Musavi, "A hybrid resonant pulse-width modulation bridgeless AC-DC power factor correction converter," IEEE Transactions on Industry Applications, vol. 53, no. 2, pp. 14061415, 2017.

[2] W.-S. Bu and L.-L. Xu, "Improved virtual-flux-linkage observation method of PWM rectifier," Applied Mechanics and Materials, vol. 678, pp. 528-532, 2014.

[3] D. Zhou, J. Zhao, and Y. Liu, "Independent control scheme for nonredundant two-leg fault-tolerant back-to-back converterfed induction motor drives," IEEE Transactions on Industrial Electronics, vol. 63, no. 11, pp. 6790-6800, 2016.

[4] M. B. Ketzer and C. B. Jacobina, "Sensorless PWM rectifiers with active filter action," in Proceedings of the 24th IEEE International Symposium on Industrial Electronics, ISIE '15, pp. 405-410, Buzios, Brazil, 2015.

[5] Z. Zeng, W. Zheng, R. Zhao, C. Zhu, and Q. Yuan, "Modeling, modulation, and control of the three-phase four-switch pwm rectifier under balanced voltage," IEEE Transactions on Power Electronics, vol. 31, no. 7, pp. 4892-4905, 2016.

[6] K. Song, G. Konstantinou, W. Mingli, P. Acuna, R. P. Aguilera, and V. G. Agelidis, "Windowed SHE-PWM of interleaved four-quadrant converters for resonance suppression in traction power supply systems," IEEE Transactions on Power Electronics, vol. 32, no. 10, pp. 7870-7881, 2017.

[7] Y. Zhang, Y. Yi, P. Dong, F. Liu, and Y. Kang, "Simplified model and control strategy of three-phase PWM current source rectifiers for DC voltage power supply applications," IEEE Journal of Emerging and Selected Topics in Power Electronics, vol. 3, no. 4, pp. 1090-1099, 2015.

[8] Y. Zhang, W. Xie, and Z.-X. Li, "Model predictive direct power control of a PWM rectifier with duty cycle optimization," IEEE Transactions on Power Electronics, vol. 28, no. 11, pp. 5343-5351, 2013.

[9] Y.-J. Wang and L. Pierrat, "Probabilistic modelling of current harmonics produced by an AC/DC converter under voltage unbalance," IEEE Transactions on Power Delivery, vol. 8, no. 4, pp. 2060-2066, 1993.

[10] J. G. Norniella, J. M. Cano, G. A. Orcajo et al., "Improving the dynamics of virtual-flux-based control of three-phase active rectifiers," IEEE Transactions on Industrial Electronics, vol. 61, no. 1, pp. 177-187, 2014.

[11] Y. Zhang, Z. Li, and Y. Zhang, "Performance improvement of direct power control of PWM rectifier with simple calculation," IEEE Transactions on Power Electronics, vol. 28, no. 7, pp. 34283437, 2013.

[12] Y. Zhang and C. Qu, "Model predictive direct power control of PWM rectifiers under unbalanced network conditions," IEEE Transactions on Industrial Electronics, vol. 62, no. 7, pp. 40114022, 2015.

[13] Z. I. Zhen-ning, L. Fei, and M. A. Ying-tao, "Research on PWM rectifiers control scheme without line voltage sensors," Electric drive, vol. 39, no. 10, pp. 27-30, 2009.

[14] U.-C. Moon, S.-E. Kim, R. Chan, and S. Kwak, "A kalman filter based predictive direct power control scheme to mitigate source voltage distortions in PWM rectifiers," Journal of Power Electronics, vol. 17, no. 1, Article ID JPE 17-1-19, pp. 190-199, 2017.

[15] S. Chattopadhyay and V. Ramanarayanan, "A voltage-sensorless control method to balance the input currents of a three-wire boost rectifier under unbalanced input voltages condition," 
IEEE Transactions on Industrial Electronics, vol. 52, no. 2, pp. 386-398, 2005.

[16] J.-H. Wang, H.-D. Li, and L.-M. Wang, "Direct power control system of three phase boost type PWM rectifiers," Proceedings of the CSEE, vol. 26, no. 18, pp. 54-59, 2006.

[17] J. Ge, Z. Zhao, L. Yuan, T. Lu, and F. He, "Direct power control based on natural switching surface for three-phase PWM rectifiers," IEEE Transactions on Power Electronics, vol. 30, no. 6, pp. 2918-2922, 2015.

[18] Y. Zhang, C. Qu, and J. Gao, "Performance Improvement of Direct Power Control of PWM Rectifier Under Unbalanced Network," IEEE Transactions on Power Electronics, vol. 32, no. 3, pp. 2319-2328, 2017.

[19] Y. Zhang, J. Gao, and C. Qu, "Relationship between two direct power control methods for PWM rectifiers under unbalanced network," IEEE Transactions on Power Electronics, vol. 32, no. 5, pp. 4084-4094, 2017.

[20] M. B. Ketzer and C. B. Jacobina, "Sensorless control technique for pwm rectifiers with voltage disturbance rejection and adaptive power factor," IEEE Transactions on Industrial Electronics, vol. 62, no. 2, pp. 1140-1151, 2015.

[21] G.-S. Lv and C.-J. Li, "Improved of star ting performance for AC voltage sensor less PWM rectifier," Power Electronics, vol. 42, no. 9, pp. 70-72, 2008.

[22] F.-J. Wu, Z.-W. Wang, and L. Sun, "Improved virtual flux oriented vector control of PWM rectifier," Dianji yu Kongzhi Xuebao/Electric Machines and Control, vol. 12, no. 5, pp. 504508, 2008.

[23] B.-H. Kwon, J.-H. Youm, and J.-W. Lim, "A line-voltagesensorless synchronous rectifier," IEEE Transactions on Power Electronics, vol. 14, no. 5, pp. 966-972, 1999.

[24] Y. Cho and K.-B. Lee, "Virtual-flux-based predictive direct power control of three-phase PWM rectifiers with fast dynamic response," IEEE Transactions on Power Electronics, vol. 31, no. 4, pp. 3348-3359, 2016.

[25] W.-S. Bu, L.-L. Zhai, X.-B. Wang, and L. Yuan, "Research on power grid voltage sensorless DPC of PWM rectifier," Electric drive, vol. 43, no. 2, pp. 50-60, 2013. 


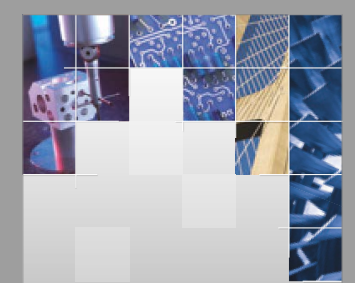

\section{Enfincering}
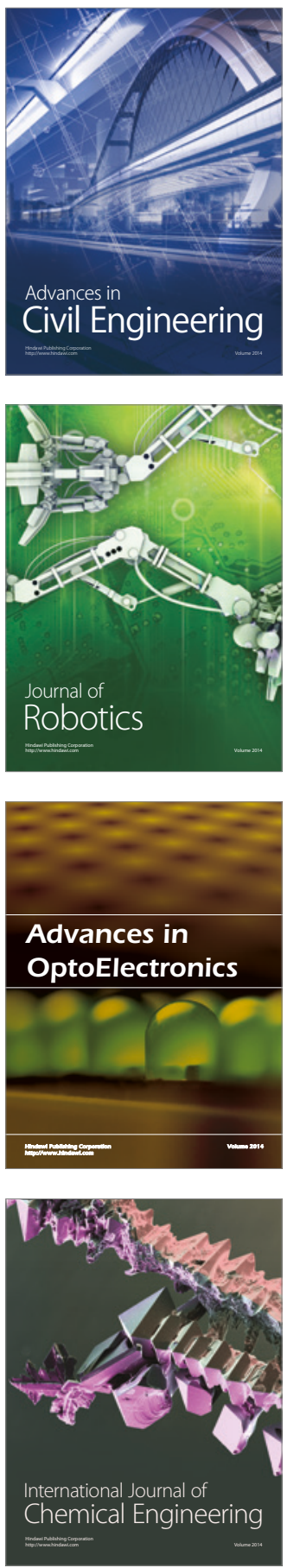

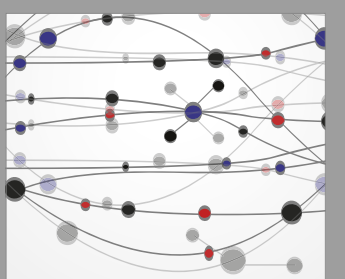

The Scientific World Journal

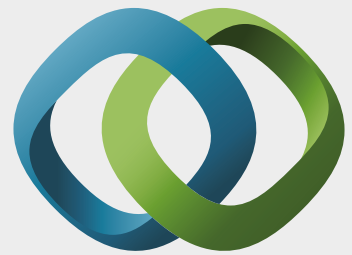

\section{Hindawi}

Submit your manuscripts at

https://www.hindawi.com
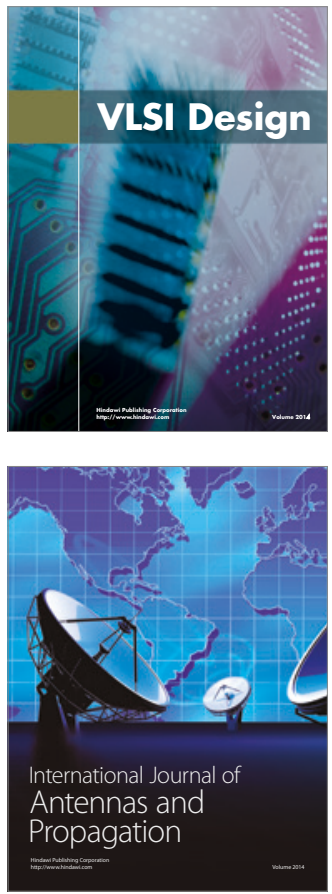

\section{Rotating}

Machinery
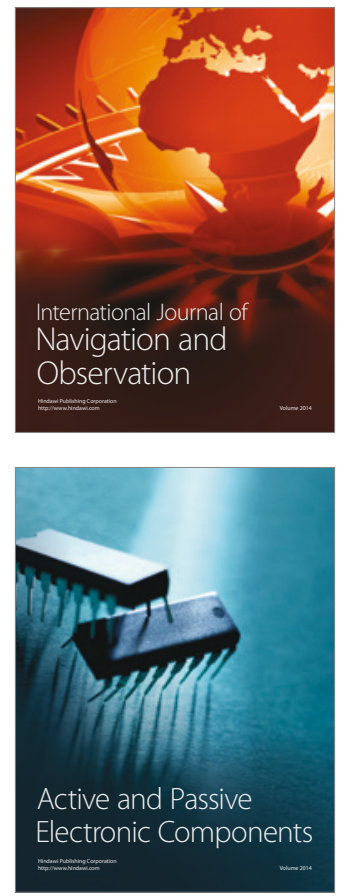
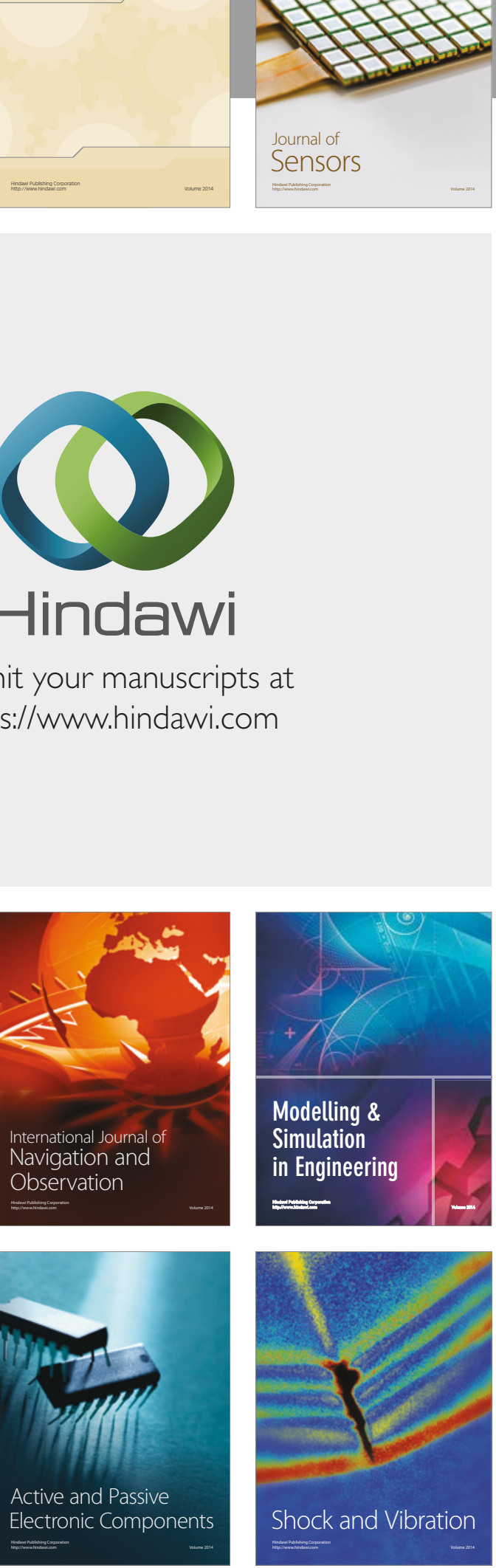
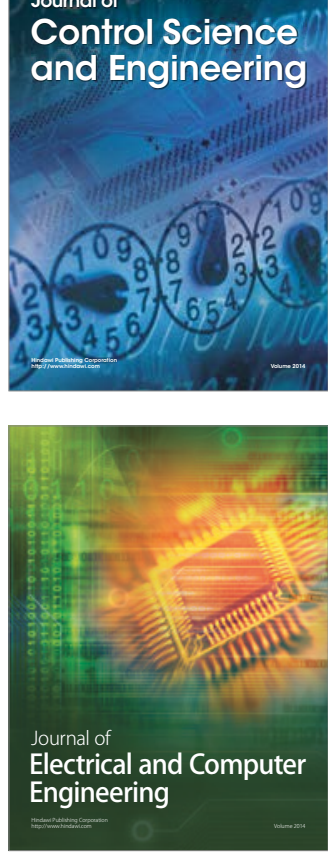

Distributed

Journal of

Control Science

and Engineering
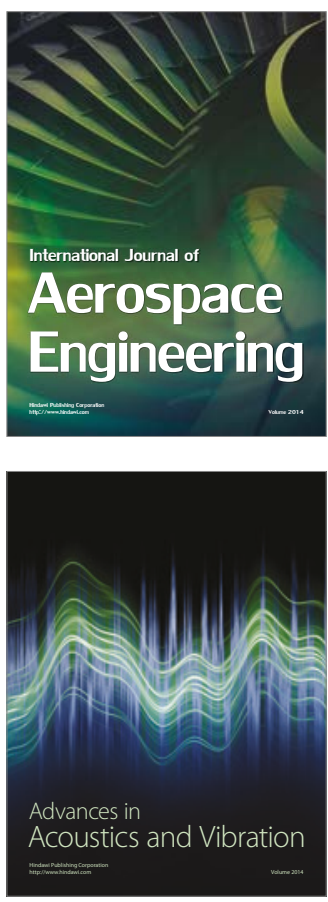

Sensor Networks 